\title{
General Research
}

\section{Voltammetric quantification of 4-nitrophenol using a multivariate optimized plated bismuth film electrode.}

Rodrigo Nu\&ntilde;ez, Jessica Moreno Betancourth, Patricia Inés Ortiz, and Valeria Pfaffen

Ind. Eng. Chem. Res., Just Accepted Manuscript • DOI: 10.1021/acs.iecr.9b01700 • Publication Date (Web): 18 Jun 2019

Downloaded from http://pubs.acs.org on June 21, 2019

\section{Just Accepted}

"Just Accepted" manuscripts have been peer-reviewed and accepted for publication. They are posted online prior to technical editing, formatting for publication and author proofing. The American Chemical Society provides "Just Accepted" as a service to the research community to expedite the dissemination of scientific material as soon as possible after acceptance. "Just Accepted" manuscripts appear in full in PDF format accompanied by an HTML abstract. "Just Accepted" manuscripts have been fully peer reviewed, but should not be considered the official version of record. They are citable by the Digital Object Identifier (DOI®). "Just Accepted" is an optional service offered to authors. Therefore, the "Just Accepted" Web site may not include all articles that will be published in the journal. After a manuscript is technically edited and formatted, it will be removed from the "Just Accepted" Web site and published as an ASAP article. Note that technical editing may introduce minor changes to the manuscript text and/or graphics which could affect content, and all legal disclaimers and ethical guidelines that apply to the journal pertain. ACS cannot be held responsible for errors or consequences arising from the use of information contained in these "Just Accepted" manuscripts. 


\title{
Voltammetric quantification of 4-nitrophenol
}

\author{
using a multivariate optimized plated bismuth
}

\section{film electrode.}

\author{
Rodrigo N. Nuñez, Jessica Moreno Betancourth, Patricia I. Ortiz and Valeria Pfaffen* \\ INFIQC-CONICET and Universidad Nacional de Córdoba. Ciudad Universitaria, 5000- \\ Córdoba, Argentina.
}

\begin{abstract}
KEYWORDS: Bismuth film electrode; Box-Behnken design; Response Surface Methodology; Nitrophenol
\end{abstract}

\begin{abstract}
In this study the multivariate optimization of bismuth film deposition (BiFE) on glassy carbon electrode, together with square wave voltametry (SWV) parameters for nitrophenol quantification is described for the first time. For this purpose response surface methodology (RSM) and desirability function (DF) were applied to a Box-Behnken design (BBD). For the BiFE deposition procedure, the relationship between the reduction current peak $\left(\mathrm{i}_{\mathrm{p}}\right)$ and standard deviation (SD) values with time, potential deposition and Bi (III) concentration were analyzed, meanwhile for frequency, step and amplitude only the relationship with $\mathrm{i}_{\mathrm{p}}$ was
\end{abstract}


considered. The $\mathrm{pH}$ influence in nitrophenol determination was carried on by univariate analysis. After parameters optimization a LOD of $3.4 \times 10^{-6}$ mol L ${ }^{-1}$ was observed.

\section{Introduction}

Application of Bismuth-film electrodes (BiFEs) was described around years 2000, showing several interesting properties such as simple preparation, high sensitivity, low toxicity, and well-defined electrochemical peaks ${ }^{1-4}$. In addition, due to the portability of the new potentiostats and accessories it is possible to carry out on site analysis with in situ plated BiFEs associated with an electroanalytical technique. Metals $5-14$ and organics 15,16,25,26,17-24 quantifications have been proposed by using BiFEs. In these articles, different procedures for obtaining the bismuth film are described; where it is varied not only the composition of the solution but also the potential and time for film deposition.

Different industries, for instance, explosives, pharmaceuticals and pesticides use aromatic nitro compounds and some of them can be toxic or harmful to humans or the environment. In the particular cases of organic compounds determination, nitrophenol (NP) is one of the selected as test analyte, since it has a reducible group that allows a good evaluation of this type of films 2,16,27-30. In the ex situ BiFE deposition different conditions 2,12,35-38,16,27,28,30-34 have been proposed, starting from the media $\mathrm{pH}$ which can be either acidic or acetate buffer with $\mathrm{pH}$ values between 4 and 5, furthermore, deposition potential is varied between -0.500 to $-1.400 \mathrm{~V}$, deposition time between 60 to 600 seconds and from $2.5 \times 10^{-4} \mathrm{~mol} \mathrm{~L}^{-1}(100 \mathrm{ppm})$ to $2.0 \times 10^{-6}$ mol L-1 (900 ppb) Bi(III) concentration. Some authors claim that they have optimized the deposition method, however, as far as we know, the experimental parameters influence on the ex situ bismuth film electrodes obtained for nitrophenol current peak determination has been limited 
to single factor analysis $2,27-29$, no papers about multifactor interaction effects of $\mathrm{Bi}(\mathrm{III})$ concentration, time and deposition potential has been reported by now.

Some methods using statistical designs of experiments, have been employed in the optimization of electrochemical sensors ${ }^{39-45}$, as they provide advantages allowing to set the optimum conditions using lower numbers of experiments. Using adequate experimental design a regression equation can be obtained were the importance of each independent variable in the global process can be obtained, furthermore the possibility of considering interaction effects between the variables can be detected, being an advantage over the classical method ${ }^{46}$. In the literature there are some reports describing multivariate optimization of the voltammetric response ${ }^{47-52}$. Furthermore, none of before mentioned articles describe NP determination.

Square wave voltammetry (SWV) is a rapid and sensitive electroanalytical technique ${ }^{53}$. In general SWV optimization has been performed by one-factor-at-a-time (OFAT) approach. $50,51,54,55$. However, we believe that all the analytical process must be optimized taking into account all the factors at once. We have already performed SWV parameters optimization for other compounds 47,48,52 and we will continue optimizing analytical techniques by using design experiments methods.

This research reports for the first time, the multifactor optimization affecting bismuth film growth on glassy carbon electrode and SWV parameters for nitrophenol quantification by using RSM a statistical and graphical technique. Particularly, 4-nitrophenol was used as reference compound, in general with electrochemical techniques related compounds show similar behaviors so the technique can be generalized to other nitrocompounds and the idea is to quantify all the nitrocompounds present in the samples. With regard to the optimization, for 
BiFE deposition, two different solutions traditionally reported were analyzed together with Bi (III) concentration, time and deposition potential. While, SWV step, amplitude and frequency parameters were considered. Furthermore, figures of merit were established for 4-nitrophenol determination and the practicality and feasibility of the sensor was verified by NP analysis in water samples.

\section{Experimental}

\subsection{Apparatus, reagents and solutions}

All the electrochemical experiments (Cyclic voltammetry $(\mathrm{CV}), \mathrm{SWV}$ and potentiostatic measurements, were described elsewhere ${ }^{56,57}$.

All reagents are analytical grade and used without further purification. Solution were prepared with Milli-Q Millipore purified water. 4-Nitrophenol (NP) and $\mathrm{Bi}\left(\mathrm{NO}_{3}\right)_{3} .5 \mathrm{H}_{2} \mathrm{O}$ were obtained from Sigma-Aldrich (St. Louis, MS, USA). All the chemical compounds used as supporting electrolyte, sodium acetate, potassium hydroxide, acetic, phosphoric, boric and hydrochloric acid were from J.T. Baker. Solution of Britton Robinson buffer (BRBS) at different $\mathrm{pH}$ values were prepared by mixing acetic, phosphoric and boric acid to a final concentration of each component of $0.04 \mathrm{~mol} \mathrm{~L}^{-1}$. The electrodeposition solution was prepared with $1 \times 10^{-3} \mathrm{~mol}$ $\mathrm{L}^{-1} \mathrm{Bi}\left(\mathrm{NO}_{3}\right)_{3} \cdot 5 \mathrm{H}_{2} \mathrm{O}$ either in acetate buffer solution $(\mathrm{ABS}) \mathrm{pH} 4.50$ or $0.10 \mathrm{~mol} \mathrm{~L}^{-1} \mathrm{HCl}$. Accuracy and applicability of the optimized method was analyzed using water samples, from Rio Tercero river, San Roque Lake, and drinking water, all samples from Córdoba, Argentina. Water samples were filtered using a Micropore membrane of $0.45 \mu \mathrm{m}$ and stored at $4{ }^{0} \mathrm{C}$ in glass containers until they were studied. Each analysis was performed by adding a $2.5 \mathrm{~mL}$ aliquot to a 
$10.0 \mathrm{~mL}$ calibrated flask, after that a NP standard solution aliquot was added to a $20 \times 10^{-6} \mathrm{~mol}$ $\mathrm{L}^{-1}$ concentration and completed with buffer solution.

\subsection{Experimental procedure}

Nitrophenol (NP) determination can be electrochemically carried out by the reduction of the nitro group that proceeds by the following two steps mechanism ${ }^{27-29}$ :

Slow: $\mathrm{R}^{-\mathrm{NO}_{2}}+\mathrm{e}^{-} \rightarrow \mathrm{R}-\mathrm{NO}_{2}-$

Fast: $\mathrm{R}^{-\mathrm{NO}_{2}-}+3 \mathrm{e}^{-}+4 \mathrm{H}^{+} \rightarrow \mathrm{R}-\mathrm{NHOH}+\mathrm{H}_{2} \mathrm{O}$

here, NP determination was evaluated by $\mathrm{CV}$ and $\mathrm{SWV}$, in both cases a negative current peak was observed. Optimization procedures were carried on to BiFE preparation deposited by $\mathrm{CV}$, and for SWV parameters for nitrophenol determination, in both cases NP concentration was 10 $\mathrm{mgL}^{-1}$.

The electrode modification under the optimized conditions established in the present article are the following: prior to modification, the GCE was polished with $0.05 \mu \mathrm{m}$ alumina slurry and then ultrasonically washed with Milli-Q water. A pretreated GCE was immersed into $\mathrm{pH} 4.50,0.1 \mathrm{~mol} \mathrm{~L}^{-1}$ acetate buffer containing $2.7 \mathrm{gL}^{-1} \mathrm{Bi}(\mathrm{III})$. The Bi film was potentiostatically electrodeposited onto the GCE at $-0.64 \mathrm{~V}$ (vs $\mathrm{Ag} / \mathrm{AgCl}$ ) for $67 \mathrm{~s}$ to form $\mathrm{BiFE} / \mathrm{GCE}$. The bismuth film is removed by applying for $60 \mathrm{~s} \mathrm{a}+0.5 \mathrm{~V}$ potential step in a BRBS solution, after that a new film is deposited.

All the experimental condition (instrumental and chemical) were analyzed and the optimized SWV procedure was: a $10 \mathrm{~mL}$ aliquot of BRBS $0.05 \mathrm{~mol} \mathrm{~L}^{-1}$, a $5 \mathrm{~s}$ equilibration time at open circuit potential, and finally a cathodic potential scan from -0.200 to $-1.000 \mathrm{~V}$ versus $\mathrm{Ag} / \mathrm{AgCl}$ 
$\left(3.0 \mathrm{~mol} \mathrm{~L}{ }^{-1} \mathrm{KCl}\right)$ at a frequency of $45 \mathrm{~Hz}$, an amplitude of $0.02 \mathrm{~V}$ and a step potential of 0.008 V. All measurements were perfomed three times $(n=3)$ for each concentration.

\subsection{Data analysis}

Design-Expert 7.0.0 software was used for experimental designs, statistical analyses, and regression models. Analysis of variance (ANOVA) was used to test the significance of each term in the equation and goodness of fit of the obtained regression model. R-squared $\left(\mathrm{R}^{2}\right)$, adjusted Rsquared $\left(\mathrm{R}^{2}{ }_{\text {adj }}\right)$ and predicted $\mathrm{R}$-squared $\left(\mathrm{R}^{2}\right.$ pre $)$, were used to check the fitness of the developed models. The significant levels are given as probability values less than 0.05 .

\subsection{Experimental design}

Response Surface Methodology (RSM) were used to find the optimized variables values for film deposition and instrumental SWV parameters. Optimization of the BiFE/GCE preparation and SWV instrument parameters were performed by following a three-level-threefactor full factorial Box-Behnken design (BBD) as already described elsewhere ${ }^{48,52,58}$. In the optimization study for BiFE preparation, deposition time (A), Bi (III) concentration (B) and deposition potential (C) were selected as independent variables, while the evaluated response was the cathodic current peak $\left(\mathrm{i}_{\mathrm{p}}\right)$ and its standard deviation (SD) (Table $\mathrm{S} 1$ ). By the other side, for SWV instrumental variables optimization, Step (A), Amplitude (B) and Frequency (C) were selected as independent variables and current peak $\left(i_{p}\right)$ as response (Table S2). Data from BBD was subjected to a multiple regression methodology to obtain the parameter estimation of the mathematical model by the quadratic polynomial equation: 


$$
Y=\beta_{0}+\sum_{i=1}^{k} \beta_{i} x_{i}+\sum_{i=1}^{k} \beta_{i i} x_{i}^{2}+\sum_{i=1}^{k-1} \sum_{j=2}^{k} \beta_{i j} x_{i} x_{j}+\varepsilon
$$

where $\mathrm{Y}$ is the predicted response, $\beta_{0}$ is an offset term, $\beta \mathrm{i}$ is the coefficient of linear effect, $\beta \mathrm{ii}$ is the coefficient of squared effect, $\beta \mathrm{ij}$ is the coefficient of interaction effect, and $\varepsilon$ is the random error. This equation may be a linear one, but it may be unsuitable to explain fully the wide range included in the factor space or to describe completely the influence of all the variables and their interactions.

On the other hand, the Derringer function (DF) as described elsewhere ${ }^{48,52,58}$ was used to find optimal compromises between the total number of responses taken into account. As already mention, this function allows to determing the levels of the predictor variables that produces the most desirables response on the dependent variables. It considers desirability 1 for maximum and 0 for minimum by the desirability profile inspection.

\section{Results and discussion}

\section{1. Comparison between GCE and BiFE}

Fig. 1 show three successively negative scans for $10 \mathrm{mg} \mathrm{L}^{-1}$ nitrophenol reduction on glassy carbon (A) and BiFE (B) electrodes obtained in 0.05 mol L $\mathrm{L}^{-1} \mathrm{ABS} \mathrm{pH} 4.5$ at $0.100 \mathrm{Vs}^{-1}$, the solution was stirred between each scan. As can be observed, both electrodes exhibit a cathodic current peak; however with a different current intensity for the same conditions. Mainly, current peak values for $\mathrm{BiFE}$ electrodes are around $23 \mu \mathrm{A}$ and almost constant for the three successive scans (Fig. 1 B), while on GCE the first scan present a current value similar to that obtained with BiFE electrode, however on the successively scans a remarkable signal decay is obtained (Fig. 1 


\begin{abstract}
A). All this suggest that BiFE electrodes are more suitable for NP quantification in successively determination as compared to GCE and will be used from now on.
\end{abstract}

\title{
3. 2. Experimental design for BiFE preparation optimization
}

In order to get the best analytical response for NP determination and reproducibility, BiFE deposition was optimized using the cathodic current peak and standard deviation (SD) as dependant variables; the measurements were performed in the two traditional solutions reported in the literature (ABS and $\mathrm{HCl}$ solutions). The purpose is to obtain a film that can be used several times. With the proposed design independent variables significance and interactions, on the negative current peak and SD for the successive scans can be explained; the design considers current peak maximization and standard deviation minimization.

In Table S1 the dependence of NP cathodic current peak values $\left(i_{p}\right)$ after blank correction with the corresponding SD, for each BBD run, both in $0.05 \mathrm{~mol} \mathrm{~L}^{-1} \mathrm{ABS}$ pH 4.5 and $1.0 \mathrm{~mol} \mathrm{~L}^{-1}$ $\mathrm{HCl}$ are presented. The analytical results were adjusted by using the least squared methodology to a polynomial function of second order. The significance for the adjustement of the multiple regression was carried on by the ANOVA test and the lack of fit (LOF) with a 0.05 significance level. The ANOVA test demonstrated that results obtained in $\mathrm{HCl}$ are not significant for all the independent variables analyzed, probably due to the irreproducibility of the current values obtained. So the analysis will be performed only with data obtained in acetate buffer.

The significant terms for the cathodic current peak $\left(i_{p}\right)$ and SD optimization, different RSquared values $\left(\mathrm{R}^{2}, \mathrm{R}^{2}\right.$ adj and $\mathrm{R}^{2}$ pred $)$, LOF $\mathrm{p}$ values and fitted model equations for semi-empirical expressions are presented in Table S3. It can be observed that leave out, the significant terms for BiFE deposition optimizations were all the three variables studied, deposition time (A), Bi(III) 
concentration (B) and deposition potential (C), but also the quadratic terms for $\mathrm{A}$ and $\mathrm{B}\left(\mathrm{A}^{2}\right.$ and $\mathrm{B}^{2}$ ). On the other side, interactions between variables or the quadratic term for $\mathrm{C}$ were not significant. The LOF p-value of 0.987 indicates that the analysis is not significant with respect to the pure error. Furthermore, the present model explains $98.6 \%$ of the total variability $\left(\mathrm{R}^{2}\right.$ adj $0.986)$ and $98.4 \%$ of new data variability $\left(\mathrm{R}^{2}\right.$ pred 0.984$)$. As the difference between both values is less than 0.2 that indicates a good model agreement.

In Fig. 2, 3D response surface plots are presented, which was adequate to determine the dependence of dependent variables on independent ones. Being the cathodic current peak the dependent variable these surface plots shows the dependence between Bi (III) concentration and deposition potential (Fig. 2A), Bi(III) concentration and deposition time (Fig. 2B) and potential and time deposition (Fig. 2C). In Fig. 2A there is a maximum (in absolute value) for intermediate Bi (III) concentration values while the current peak value increases with decreasing deposition potential at a constant $60 \mathrm{~s}$ deposition time. Fig. 2B shows a maximum in the response for intermediate $\mathrm{Bi}$ (III) concentration values and deposition time at a constant $-0.76 \mathrm{~V}$ deposition potential. Finally, Fig. $2 \mathrm{C}$ shows the behavior between potential and time deposition at a constant $2.75 \mathrm{~g} \mathrm{~L}^{-1} \mathrm{Bi}$ (III) concentration. The surface plot describes a similar shape as Fig. 2A with a maximum response at intermediate deposition time values. Response surface analysis show the significance of the quadratic terms corresponding to $\mathrm{Bi}(\mathrm{III})$ concentration and deposition time.

On the other hand, when analyzing the ANOVA results for SD (Table S3) only A and C are significant while the LOF has a p-value of 0.9836 . Data of SD were transformed to base 10 $\log$ and the R-square values were $0.697\left(\mathrm{R}^{2}\right), 0.646\left(\mathrm{R}_{\text {adj }}\right)$ and $0.605\left(\mathrm{R}^{2}\right.$ pred $)$, as already mentioned the difference between the last two values is less than 0.2. Although in the case of SD 
the model explains $60.5 \%$ of the total variability and $64.6 \%$ of the new data variability, the results are considered satisfactory.

Fig. 3 shows $3 \mathrm{D}$ response surface plot for SD vs potential and time deposition at a constant $2.75 \mathrm{mg} \mathrm{L}^{-1} \mathrm{Bi}$ (III) concentration. As it can be observed, there is a SD decreases as both time and deposition potential increase.

Considering that only, deposition and time potential are significant for SD model and comparing Fig $2 \mathrm{C}$ and Fig 3 , where it can be seen that optimum conditions for $\mathrm{i}_{\mathrm{p}}$ maximization and SD minimization are opposed, other tools must be used. To achieve this purpose the desirability function (DF) was obtained by maximizing current peak values and minimizing SD for the all three independent variables. To obtain the best operational conditions, cathodic current peak values (as absolute value) maximization with a $+++++(5$ of 5$)$ significance and SD minimization with a $+++(3$ of 5) significance for the three responses each with a new BiFE were obtained.

Fig. 4 presents the desirability function for the three analyzed variables, deposition time (Fig. 4A), Bi (III) concentration (Fig 4B) and deposition potential (Fig. 4C). As it can be observed, in Figs $4 \mathrm{~A}$ and $\mathrm{B}$, maximum $\mathrm{DF}$ values are obtained for intermediate deposition time and $\mathrm{Bi}$ (III) concentration values. While, in the case of deposition potential (Fig. 4C) a slight variation of DF is observed. From the DF analysis, the highest desirability score obtained was 0.851 for $67 \mathrm{~s}$ deposition time, $2.7 \mathrm{mg} \mathrm{L}^{-1} \mathrm{Bi}$ (III) concentration and $0.600 \mathrm{~V}$ deposition potential. This set of conditions was determined to be the optimum and to confirm the optimized condition validity. To compared experimental results with model predicted values different experiments were performed and a $-19.97 \mu \mathrm{A}$ NP reduction current peak was obtained with a prediction interval of 
$95 \%$ between $-20.43 \mu \mathrm{A}$ and $-19.52 \mu \mathrm{A}$. Furthermore, using three different BiFEs for $10 \mathrm{mg} \mathrm{L}^{-1}$ NP a current value of $-19.7 \pm 0.4 \mu \mathrm{A}$ was obtained. The results of the comparison between the obtained mean values with the predicted one indicates that the developed quadratic model is adequate.

\section{3. Optimization of the $\mathrm{pH}$ value determination}

To obtain the best $\mathrm{pH}$ value for NP quantification, BRBS at different $\mathrm{pH}$ values were used. Fig. 5 presents the negative scans for $10 \mathrm{mg} \mathrm{L}^{-1} \mathrm{NP}$ at $0.100 \mathrm{Vs}^{-1}$ in BRBS at the following $\mathrm{pH} 3$, 5, 7 and 9. As already reported, better signals are obtained at acid $\mathrm{pH}$ in agreement with the proposed mechanism ${ }^{27-29}$. Particularly, in this case as demonstrated by Fig. 5, a well defined current peak is obtained for $\mathrm{pH}$ values lower than 7 and the maximum reduction current peak is defined at $\mathrm{pH}$ 5. For alkaline solutions $(\mathrm{pH} 9)$, the signal is much lower and even two different peaks can be detected, indicating that different process are taking place. For that reason, $\mathrm{pH} 5$ was chosen as the working value.

\section{4. Optimization of instrumental variables}

Nitrophenol quantification was performed by an electrochemical method, consisting on an equilibration time followed by SWV using a BiFE modified glassy carbon electrode. In the present study, the optimization of SWV variables such as amplitude, frequency and step potential using three independent factors and the current reduction peak as response variable was carried on. The Box-Behnken design is presented in Table S2 along with experimental data, all current peak values $\left(i_{p}\right)$ were blank corrected, and the experiments were performed in $0.05 \mathrm{~mol} \mathrm{~L}^{-1}$ BRBS $\mathrm{pH}=5.0$. It is worth noting that reduction current peak values for SWV are somehow 
smaller than those for $\mathrm{CV}$, as the studied electrochemical process is irreversible. However, SWV is a faster technique.

The variables analyzed were step potential (A), amplitude (B) and frequency (C), and as previously reported an ANOVA test was performed. The significant terms for the cathodic current peak $\left(i_{p}\right)$ and SD optimization, different $R$-Squared values $\left(R^{2}, R_{\text {adj }}^{2}\right.$ and $\left.R_{\text {pred }}^{2}\right)$, LOF $p$ values and fitted model equations for semi-empirical expressions are presented in Table S3, together with the already discussed analysis for BiFE formation. As it can be observed from Table S3, all the three variables studied were significant, and also the quadratic term for step potential $\left(\mathrm{A}^{2}\right)$. On the other hand interactions between variables or the quadratic terms for $\mathrm{B}$ and $\mathrm{C}$ were not significant. The LOF p-value of 0.964 indicates that the analysis is not significant with respect to the pure error. Furthermore, the $\mathrm{R}^{2}$ adj value $(0.981)$ and $\mathrm{R}^{2}$ pred $(0.978)$ demonstrate that $98.1 \%$ of the model variability and $97.8 \%$ of new data variability can be explained by the model. Again there is a correspondence between both values as they present difference less than 0.2 indicating a reasonable agreement.

Fig. 6 presents 3D plots of the polynomial equation (Table S3) for the dependence $i_{p}$ as a function of the significant variables. Fig. $6 \mathrm{~A}$ shows the variation of $i_{p}$ as a function of the amplitude and step potential at $50 \mathrm{~Hz}$ frequency, as it can be observed there is a current increase as the amplitude increases, while for the step potential there is an increase up to intermediate values and then remains practically constant. In Fig. $6 \mathrm{~B}$ the dependant variable is represented vs SWV frequency and amplitude at a $0.008 \mathrm{~V}$ constant step, in this case there is a clear current increase as the amplitude increases while there is slight current increase as the frequency decreases. Finally, when analyzing the effects of frequency and step potential on the reduction current peak with constant $0.02 \mathrm{~V}$ amplitude (Fig. 6C), the same behavior previously described 
for both variables is observed. The quadratic term for the step potential $\left(\mathrm{A}^{2}\right)$ although significant, does not have a notorious influence on the results (Figs. 6A and C).

As already mentioned before the dependent variable value $\left(\mathrm{i}_{\mathrm{p}}\right)$ was maximized to 1.0 with a $+++++(5$ of 5$)$ significance. On the basis of these calculations, the optimized $i_{p}$ reduction was $8.9 \pm 0.5 \mu \mathrm{A}$ with a $95 \%$ of confidence, obtained using the proposed model and the following instrumental values $45.0 \mathrm{~Hz}$ frequency, $0.008 \mathrm{~V}$ step potential and $0.02 \mathrm{~V}$ amplitude. In order to check the validity of the model different experiments were performed by triplicate and results compared to predicted values. Under the optimal condition the cathodic current peak of $10 \mathrm{mg} \mathrm{L}$ ${ }^{1} \mathrm{NP}$ was $8.4 \pm 0.3 \mu \mathrm{A}$. The results of the comparison between the obtained mean values with the predicted one indicate that the developed quadratic equation is adequate.

\section{5. Method performance}

The method linearity was tested in the $(1.0-100) \times 10^{-6} \mathrm{~mol} \mathrm{~L}^{-1} \mathrm{NP}$ concentration range by measuring triplicate samples, prepared at five concentration levels. Data of $i_{p}$ vs. concentration were fitted by least-squares obtaining a $\mathrm{R}^{2}$ value greater than 0.999 . The detection limit (LOD) and quantification limit (LOQ) were calculated as described elsewhere ${ }^{59}$, the obtained values were $3.4 \times 10^{-6} \mathrm{~mol} \mathrm{~L}^{-1}$ and $1.0 \times 10^{-5} \mathrm{~mol} \mathrm{~L}^{-1}$ respectively, and the resulting equation is:

$$
i_{p}(\mu A)=(1.34 \pm 0.03)+(5.99 \pm 0.08) \times 10^{4} C_{N P}\left(\mu \mathrm{Amol}^{-1} L^{-1}\right)
$$

Repeatability (intra-assay precision studies) was analyzed, by the same analyst, under the same conditions, and on the same day using three different levels of concentration $\left(5.00 \times 10^{-5}\right.$, $7.00 \times 10^{-5}$, and $9.00 \times 10^{-5} \mathrm{~mol} \mathrm{~L}^{-1}$ ) with six replicate samples. Table 1 shows the coefficient of variation $(\mathrm{CV} \%)$ values for different NP concentrations and results at intermediate precision for 
current peaks values under different conditions. In general it can be observed that, CV values are close to $5 \%$ being an indication of an excellent precision. Intermediate precision was also analyzed by considering three replicates samples at $5.00 \times 10^{-5} \mathrm{~mol} \mathrm{~L}^{-1}$ by the same analyst, under the same conditions, on three different days (day 1, 2 and 3) for three different BiFE (I, II and III). The ANOVA test presented in Table 1 shows that there are no significant differences at $95 \%$ confidence, between the calculated averages $(p=0.398)$.

The accuracy was obtained by analyzing samples with known concentrations at three levels and comparing the experimental concentration with the true value. In Table 1 real and averages concentration values and Student's t-test $p$ values are presented, and at $95 \%$ confidence level no statistical differences were observed.

The analysis method presented in this paper was used to NP detection in water samples to validate the application potential in practical analysis. Water samples were prepared as described in Experimental section, and determinations were carried on by the standard addition method. In Table 2, NP concentration added and found, SD and recovery $\%$ are presented, the obtained results are satisfactory with a $103 \%$ average recovery, indicating that the developed method is adequate. It is worthy to note that recovery analysis in different samples and matrixes (Table 1 and Table 2) with results rounding $100 \%$ are an indication that no interferents are present in the sample.

\section{Conclusion}

This article described the development of an alternative electroanalytical method, using bismuth film electrodes, for nitrophenol quantification. The proposed methodology included a 
previous bismuth film preparation and then SWV determination. The experimental variables were studied and optimized by BBD together with RSM and DF. The proposed model allows the analysis of the different effects of independent variables, such as $\mathrm{Bi}(\mathrm{III})$ concentration and electrolyte $\mathrm{pH}$ solution, and time and deposition potential for BiFE preparation and SWV instrumental variables for a better understanding on NP detection. The quadratic response surface models is in very well agreement with data at different conditions. From the statistical analysis optimal conditions for the analytical method for NP determination was developed. To the best of our knowledge, the use of experimental design for ex situ BiFE preparation together with NP quantification by SWV is reported for the first time, good linearity range together with acceptable LOD and LOQ were obtained making the method a good candidate for a reference one. Finally, the application of the method to NP detection in natural water samples has been successful.

\section{AUTHOR INFORMATION:}

\section{Corresponding Author}

*Corresponding Author: Dr. Valeria Pfaffen, E-mail address: mpfaffen@fcq.unc.edu.ar, Phone: $+543514353866$

\section{Author Contributions}

The manuscript was written through contributions of all authors. All authors have given approval to the final version of the manuscript. 


\section{ACKNOWLEDGMENT:}

CONICET and UNC support by offering facilities and funds used in this investigation are acknowledged. Economic supports by SeCyT-UNC, project resolution 113/17, FONCyT, project PICT 12/0634, and CONICET, PIP 112-201101-00579, are gratefully acknowledged. R.N.N. and J.M.B. wish to thanks the respectively CONICET doctoral fellowship. P.I.O. and V.P. are members of CICyT CONICET, the National Science Foundation of Argentina.

\section{Supporting Information}

This file presents Tables containing coded and actual levels of variables considered for Matrix of variables for bismuth film deposition (S1) and variables for SWV (S2). Also Box-Behnken design for bismuth deposition variables (S1), instrumental SWV variables (S2) and the respective responses. Finally, a Table with significant terms and statistics summary of response surface models for bismuth film deposition and SWV optimizations is included (S3).

\section{REFERENCES:}

(1) Wang, J.; Lu, J.; Hocevar, S.; Farias, P.; Ogorevc, B. Bismuth-coated carbon electrodes for anodic stripping voltammetry. Anal. Chem. 2000, 72 (14), 3218-3222.

(2) Hutton, E. a; Ogorevc, B.; Hočevar, S. B.; Weldon, F.; Smyth, M. R.; Wang, J. An introduction to bismuth film electrode for use in cathodic electrochemical detection. Electrochem. commun. 2001, 3 (12), 707-711. 
(3) Economou, A. Bismuth-film electrodes: recent developments and potentialities for electroanalysis. TrAC Trends Anal. Chem. 2005, 24 (4), 334-340.

(4) Wang, J. Stripping Analysis at Bismuth Electrodes: A Review. Electroanalysis 2005, 17 (15-16), 1341-1346.

(5) Arduini, F.; Quintana Calvo, J.; Amine, A.; Palleschi, G.; Moscone, D. Bismuth-modified electrodes for lead detection. TrAC Trends Anal. Chem. 2010, 29 (11), 1295-1304.

(6) Serrano, N.; Alberich, A.; Díaz-Cruz, J. M.; Ariño, C.; Esteban, M. Coating methods, modifiers and applications of bismuth screen-printed electrodes. TrAC - Trends Anal. Chem. 2013, 46, 15-29.

(7) Kokkinos, C.; Economou, A. Disposable Nafion-modified micro-fabricated bismuth-film sensors for voltammetric stripping analysis of trace metals in the presence of surfactants. Talanta 2011, 84 (3), 696-701.

(8) Jovanovski, V.; Hočevar, S. B.; Ogorevc, B. Bismuth electrodes in contemporary electroanalysis. Curr. Opin. Electrochem. 2017, 114-122.

(9) Grabarczyk, M.; Wasag, J. Determination of trace amounts of Ga(III) by adsorptive stripping voltammetry with in situ plated bismuth film electrode. Talanta 2015, 144, $1091-1095$.

(10) Rocha, L. S.; Galceran, J.; Puy, J.; Pinheiro, J. P. Determination of the Free Metal Ion Concentration Using AGNES Implemented with Environmentally Friendly Bismuth Film Electrodes. Anal. Chem. 2015, 87 (12), 6071-6078.

(11) Rutyna, I.; Korolczuk, M. Determination of ultratrace thallium(I) by anodic stripping 
voltammetry at bismuth film electrodes following double deposition and stripping steps. Electroanalysis 2014, 26 (12), 2639-2643.

(12) Dal Borgo, S.; Jovanovski, V.; Pihlar, B.; Hocevar, S. B. Operation of bismuth film electrode in more acidic medium. Electrochim. Acta 2015, 155, 196-200.

(13) Wegiel, K.; Jedlińska, K.; Baś, B. Application of bismuth bulk annular band electrode for determination of ultratrace concentrations of thallium(I) using stripping voltammetry. $J$. Hazard. Mater. 2016, 310 (I), 199-206.

(14) Li, H.; Li, J.; Yang, Z.; Xu, Q.; Hou, C.; Peng, J.; Hu, X. J. Simultaneous determination of ultratrace lead and cadmium by square wave stripping voltammetry with in situ depositing bismuth at Nafion-medical stone doped disposable electrode. Hazard. Mater. 2011, 191 (1-3), 26-31.

(15) Rutyna, I. Determination of Folic Acid at a Bismuth Film Electrode by Adsorptive Stripping Voltammetry. Anal. Lett. 2015, 48 (10), 1593-1603.

(16) Gerent, G. G.; Gonçalves, C. Q.; Da Silva, P. S.; Spinelli, A. In situ bismuth-film electrode for square-wave cathodic voltammetric detection of pendimethalin at nanomolar level. Electrochim. Acta 2015, 168, 379-385.

(17) Levent, A.; Altun, A.; Tas, S.; Yardim, Y.; Sentürk, Z. Voltammetric Behavior of Testosterone on Bismuth Film Electrode: Highly Sensitive Determination in Pharmaceuticals and Human Urine by Square-Wave Adsorptive Stripping Voltammetry. Electroanalysis 2015, 27 (5), 1219-1228.

(18) Sá, É. S.; Da Silva, P. S.; Jost, C. L.; Spinelli, A. Electrochemical sensor based on 
bismuth-film electrode for voltammetric studies on vitamin B2 (riboflavin). Sensors Actuators B Chem. Chem. 2015, 209, 423-430.

(19) Deýlová, D.; Vyskočil, V.; Barek, J.; Economou, A. Bismuth film electrode at a silver solid amalgam substrate as a new tool for voltammetric determination of electrochemically reducible organic compounds. Talanta 2012, 102, 68-74.

(20) Deỳlová, D.; Vyskocil, V.; Economou, A.; Mansfeldová, V.; Barek, J. A new type of large-surface bismuth film electrode on a silver solid amalgam substrate and its application for the voltammetric determination of 5-nitrobenzimidazole. Int. $J$. Electrochem. Sci. 2014, 9 (8), 4653-4664.

(21) Prchal, V.; Ottenschlagerova, A.; Vyskocil, V.; Barek, J. Voltammetric Determination of 5-nitroindazole using a Bismuth Bulk Electrode. Anal. Lett. 2016, 49 (1), 49-55.

(22) Nigović, B.; Šimunić, B.; Hocevar, S. Voltammetric measurements of aminosalicylate drugs using bismuth film electrode. Electrochim. Acta 2009, 54 (24), 5678-5683.

(23) Sopha, H.; Hocevar, S. B.; Pihlar, B.; Ogorevc, B. Bismuth film electrode for stripping voltammetric measurement of sildenafil citrate. Electrochim. Acta 2012, 60, 274-277.

(24) Kreft, G. L.; De Braga, O. C.; Spinelli, A. Analytical electrochemistry of vitamin B12 on a bismuth-film electrode surface. Electrochim. Acta 2012, 83, 125-132.

(25) De Lima, C. A.; Spinelli, A. Electrochemical behavior of progesterone at an ex situ bismuth film electrode. Electrochim. Acta 2013, 107, 542-548.

(26) Gerent, G. G.; Spinelli, A. Environmentally-friendly in situ plated bismuth-film electrode for the quantification of the endocrine disruptor parathion in skimmed milk. J. Hazard. 
Mater. 2016, 308, 157-163.

(27) Hutton, E. A.; Ogorevc, B.; Smyth, M. R. Cathodic electrochemical detection of nitrophenols at a bismuth film electrode for use in flow analysis. Electroanalysis 2004, 16 (19), 1616-1621.

(28) Marcel, M.; Nunes, J.; Spinelli, A. Desenvolvimento de metodologia analítica baseada em eletrodo de carbono vítreo modificado com filme de bismuto: Aplicação em águas de chuva de regiões de Santa Catarina. Eclética Quim. 2011, 36 (2), 158-181.

(29) Asadpour-Zeynali, K.; Najafi-Marandi, P. Bismuth modified disposable pencil-lead electrode for simultaneous determination of 2-nitrophenol and 4-nitrophenol by net analyte signal standard addition method. Electroanalysis 2011, 23 (9), 2241-2247.

(30) Anik, Ü.; Çubukçu, M.; Çevik, S.; Timur, S. Usage of bismuth film electrode as biosensor transducer for alkaline phosphatase assay. Electroanalysis 2010, 22 (13), 1519-1523.

(31) Metelka, R.; Bobrowski, A.; Norkus, E.; Kalcher, K.; Vyt, K. Bismuth-film-plated carbon paste electrodes. Electrochem. commun. 2002, 4, 193-196.

(32) Campestrini, I.; de Braga, O. C.; Vieira, I. C.; Spinelli, A. Application of bismuth-film electrode for cathodic electroanalytical determination of sulfadiazine. Electrochim. Acta 2010, 55 (17), 4970-4975.

(33) Yang, M.; Zhang, Z.; Hu, Z.; Li, J. Differential pulse anodic stripping voltammetry detection of metallothionein at bismuth film electrodes. Talanta 2006, 69 (5), 1162-1165.

(34) Zhao, G.; Wang, H.; Liu, G.; Wang, Z. Box-Behnken response surface design for the optimization of electrochemical detection of cadmium by Square Wave Anodic Stripping 
Voltammetry on bismuth film/glassy carbon electrode. Sensors Actuators, B Chem. 2016, $235,67-73$.

(35) Du, D.; Ye, X.; Zhang, J.; Liu, D. Cathodic electrochemical analysis of methyl parathion at bismuth-film-modified glassy carbon electrode. Electrochim. Acta 2008, 53 (13), 44784484.

(36) Ananthi, A.; Kumar, S. S.; Phani, K. L. Facile one-step direct electrodeposition of bismuth nanowires on glassy carbon electrode for selective determination of folic acid. Electrochim. Acta 2015, 151, 584-590.

(37) Mirceski, V.; Sebez, B.; Jancovska, M.; Ogorevc, B.; Hocevar, S. B. Mechanisms and kinetics of electrode processes at bismuth and antimony film and bare glassy carbon surfaces under square-wave anodic stripping voltammetry conditions. Electrochim. Acta 2013, 105, 254-260.

(38) Serrano, N.; Alberich, A.; Dîaz-Cruz, J. M.; Ariño, C.; Esteban, M. Signal splitting in the stripping analysis of heavy metals using bismuth film electrodes: Influence of concentration range and deposition parameters. Electrochim. Acta 2008, 53 (22), 66166622.

(39) Zhou, J.; Yu, X.; Ding, C.; Wang, Z.; Zhou, Q.; Pao, H.; Cai, W. Optimization of phenol degradation by Candida tropicalis Z-04 using Plackett-Burman design and response surface methodology. J. Environ. Sci. 2011, 23 (1), 22-30.

(40) Kazemi, S. Y.; Hamidi, A. sadat; Asanjarani, N.; Zolgharnein, J. Optimization of a new polymeric chromium (III) membrane electrode based on methyl violet by using 
experimental design. Talanta 2010, 81 (4-5), 1681-1687.

(41) Farhadi, K.; Bahram, M.; Shokatynia, D.; Salehiyan, F. Optimization of polymeric triiodide membrane electrode based on clozapine-triiodide ion-pair using experimental design. Talanta 2008, 76 (2), 320-326.

(42) El Hourch, M.; Dudoit, A.; Amiard, J. C. Optimization of new voltammetric method for the determination of metallothionein. Electrochim. Acta 2003, 48 (27), 4083-4088.

(43) Li, M.; Feng, C.; Zhang, Z.; Chen, R.; Xue, Q.; Gao, C.; Sugiura, N. Optimization of process parameters for electrochemical nitrate removal using Box-Behnken design. Electrochim. Acta 2010, 56 (1), 265-270.

(44) Zhang, C.; Yang, L.; Rong, F.; Fu, D.; Gu, Z. Boron-doped diamond anodic oxidation of ethidium bromide: Process optimization by response surface methodology. Electrochim. Acta 2012, 64, 100-109.

(45) Nosuhi, M.; Nezamzadeh-Ejhieh, A. High catalytic activity of Fe(II)-clinoptilolite nanoparticales for indirect voltammetric determination of dichromate: Experimental design by response surface methodology (RSM). Electrochim. Acta 2017, 223, 47-62.

(46) Montgomery, D. Design and analysis of experiments, 3rd ed.; John Wiley and Sons: New York, 1991.

(47) Cuéllar, M.; Pfaffen, V.; Ortiz, P. I. Application of multi-factorial experimental design to successfully model and optimize inorganic chromium speciation by square wave voltammetry. J. Electroanal. Chem. 2016, 765, 37-44.

(48) Bia, G.; Borgnino, L.; Ortiz, P. I.; Pfaffen, V. Multivariate optimization of square wave 
voltammetry using bismuth film electrode to determine atrazine. Sensors Actuators B Chem. 2014, 203, 396-405.

(49) Teófilo, R. F.; Reis, E. L.; Reis, C.; Silva, G. A.; Kubota, L. T. Experimental Design Employed to Square Wave Voltammetry Response Optimization for the Glyphosate Determination. J. brazilian Chem. Soc. 2004, 15 (6), 865-871.

(50) Krepper, G.; Resende de Cerqueira, P. B.; Pistonesi, M. F.; Di Nezio, M. S.; Centurión, M. E. Determination of cadmium residues in bee products using a "lab-made" bismuth bulk electrode. Int. J. Environ. Anal. Chem. 2016, 96 (14), 1331-1340.

(51) Krepper, G.; Pierini, G. D.; Pistonesi, M. F.; Di Nezio, M. S. "In-situ" antimony film electrode for the determination of tetracyclines in Argentinean honey samples. Sensors Actuators, B Chem. 2017, 241, 560-566.

(52) Betancourth, J. M.; Cuellar, M.; Ortiz, P. I.; Pfaffen, V. Multivariate cathodic square wave stripping voltammetry optimization for nitro group compounds determination using antimony film electrodes. Microchem. J. 2018, 139.

(53) Brett, C. M.; Brett, A. M. . Electrochemistry: Principles, Methods, and Applications; Oxford University Press Inc: New York, 1993.

(54) Dos Santos, L. B. O.; Abate, G.; Masini, J. C. Determination of atrazine using square wave voltammetry with the Hanging Mercury Drop Electrode (HMDE). Talanta 2004, 62 (4), 667-674.

Ly, S. Y.; Kim, D. H.; Kim, M. H. Square-wave cathodic stripping voltammetric analysis of RDX using mercury-film plated glassy carbon electrode. Talanta 2002, 58 (5), 919- 
926.

(56) Bia, G.; Borgnino, L.; Ortiz, P. I.; Pfaffen, V. Multivariate optimization of square wave voltammetry using bismuth film electrode to determine atrazine. Sensors Actuators, B Chem. 2014, 203, 396-405.

(57) Betancourth, J. M.; Cuellar, M.; Ortiz, P. I.; Pfaffen, V. Multivariate cathodic square wave stripping voltammetry optimization for nitro group compounds determination using antimony film electrodes. Microchem. J. 2018, 139, 139-149.

(58) Cuéllar, M.; Pfaffen, V.; Ortiz, P. I. Application of multi-factorial experimental design to successfully model and optimize inorganic chromium speciation by square wave voltammetry. J. Electroanal. Chem. 2016, 765, 37-44.

(59) Miller, J. N.; Miller, J. C. Statistics and Chemometrics for Analytical Chemistry, Fifth.; Ellison Horwood: Chichester, 2005. 


\section{FIGURES}

Figure 1. Successive linear scan for $10 \mathrm{mg} \mathrm{L}^{-1} \mathrm{NP}$ in acetate buffer $\mathrm{pH} 4.5$ (black) of $1^{\text {st }}$ scan (red); $2^{\text {nd }} \operatorname{scan}\left(\right.$ green) and $3^{\text {rd }}$ scan (blue) at (A) GCE and (B) BiFE electrodes, $v=0.100 \mathrm{~V} \mathrm{~s}^{-1}$.

Figure 2. Response surface of the current peak for the Box Behnken designs of data in Table S1: (A) Deposition potential (V) vs Bi (III) concentration (mg L-1), (B) Bi (III) concentration (mg L${ }^{1}$ ) vs Deposition time (s), (C) Deposition potential (V) vs Deposition time (V).

Figure 3. Response surface of the Standard Deviation for the Box Behnken designs of data in Table S1: Deposition potential (V) vs Deposition time (V).

Figure 4. Desirability function profiles for (A) Deposition Time, (B) Bi (III) concentration and (C) Deposition potential.

Figure 5. Linear scan obtained in supporting electrolyte (dashed line) and $10 \mathrm{mg} \mathrm{L}^{-1} \mathrm{NP}$ (solid line) in $0.05 \mathrm{~mol} \mathrm{~L}^{-1}$ of different $\mathrm{pH} 3.0$ (black); 5.0 (red); 7.0 (blue) and 9.0 (dark cyan) at a BiFE electrode, $\mathrm{v}=0.100 \mathrm{~V} \mathrm{~s}^{-1}$.

Figure 6. Response surface of the current peak for the Box Behnken of data in Table S2: (A) Amplitude (V) vs Step potential (V), (B) Frequency (Hz) vs Amplitude (V) and (C) Frequency (Hz) vs Step potential (V). 


\section{TABLES}

Table 1. Analysis of known concentration samples

\begin{tabular}{|c|c|c|c|c|}
\hline \multicolumn{5}{|c|}{ Concentration } \\
\hline Real (x 10-5 $\left.\mathrm{mol} \mathrm{L}^{-1}\right)$ & \multicolumn{2}{|c|}{ Obtained $\left(\times 10^{-5} \mathrm{~mol} \mathrm{~L}^{-1}\right) \pm \mathrm{SD}^{\mathrm{a}}$} & $\mathrm{CV}^{\mathrm{b}}(\%)$ & $p$-value \\
\hline 5,00 & \multicolumn{2}{|c|}{$4,9 \pm 0,2$} & 3,50 & 0,2892 \\
\hline 7,00 & \multicolumn{2}{|c|}{$7,0 \pm 0,1$} & 1,74 & 0,5301 \\
\hline \multirow[t]{3}{*}{9,00} & \multicolumn{2}{|c|}{$8,7 \pm 0,4$} & 3.72 & 0,6443 \\
\hline & \multicolumn{2}{|c|}{ Current peak $(\mu \mathrm{A})$} & & \\
\hline & Day 1 & Day 2 & Day 3 & $p$-value \\
\hline BiFE I & 4,129 & 4,340 & 4,152 & 0,398 \\
\hline BiFE II & 4,286 & 4,473 & 4,377 & \\
\hline BiFE III & 4,364 & 4,295 & 4,226 & \\
\hline
\end{tabular}

${ }^{\mathrm{a}}$ Mean values and standard deviation of six determinations. ${ }^{\mathrm{b}} \mathrm{CV}$ : coefficient of variation. 
Table 2. Results for the detection of NP in several water samples.

\begin{tabular}{ccccc}
\hline Sample & Added $\left(\times 10^{-6} \mathrm{~mol} \mathrm{~L}^{-1}\right)$ & Found $\left(\times 10^{-6} \mathrm{~mol} \mathrm{~L}^{-1}\right)^{\mathrm{a}}$ & SD & Recovery (\%) \\
\hline San Roque lake & 20 & 20 & 4 & 102 \\
\hline Rio Tercero river & 20 & 19.5 & 0.7 & 98 \\
\hline Córdoba city drinking water & 20 & 21 & 1 & 106 \\
\hline
\end{tabular}

aSWV measurements were repeated five times $(n=3)$. 
Figure 1

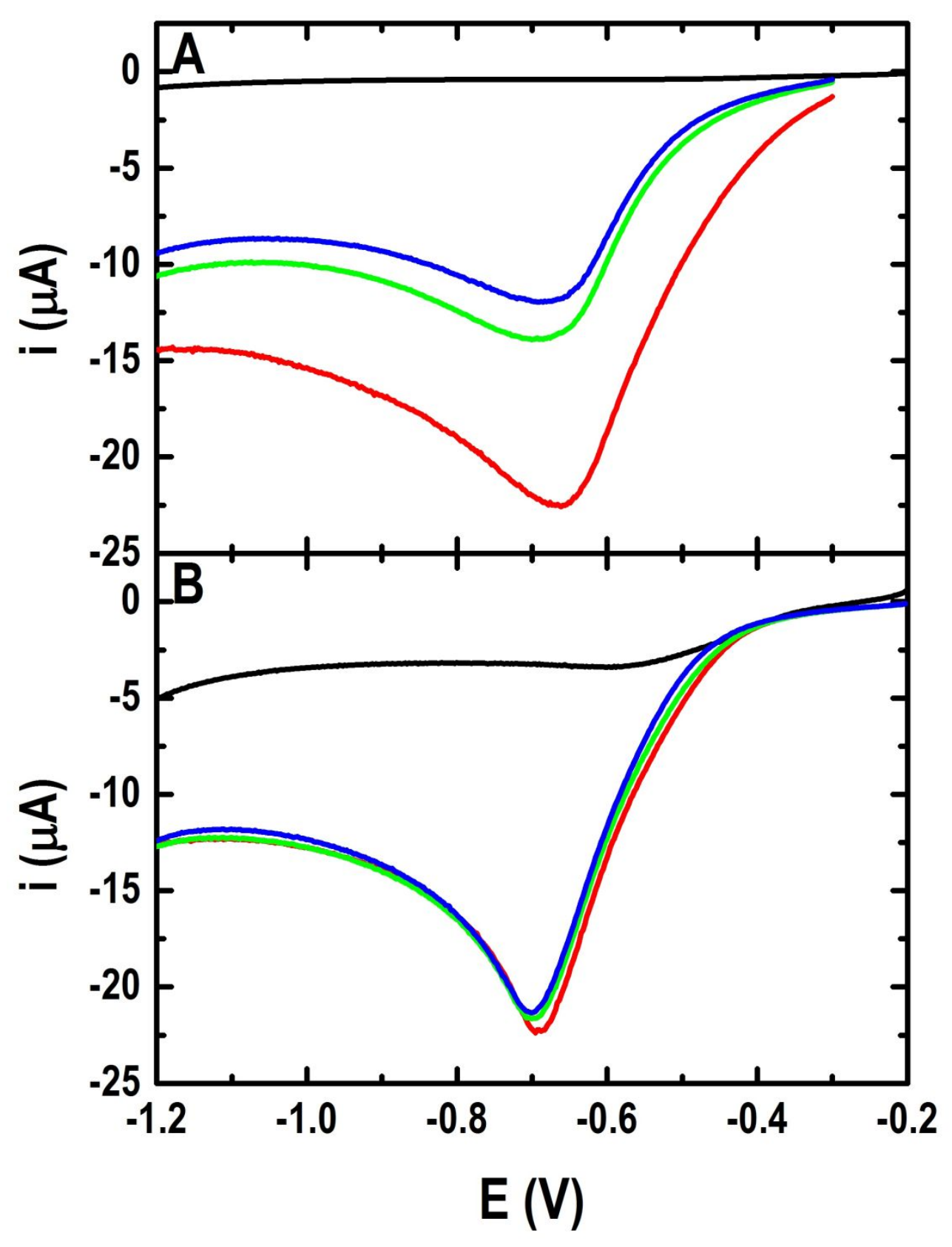

ACS Paragon Plus Environment 


\section{Figure 2}
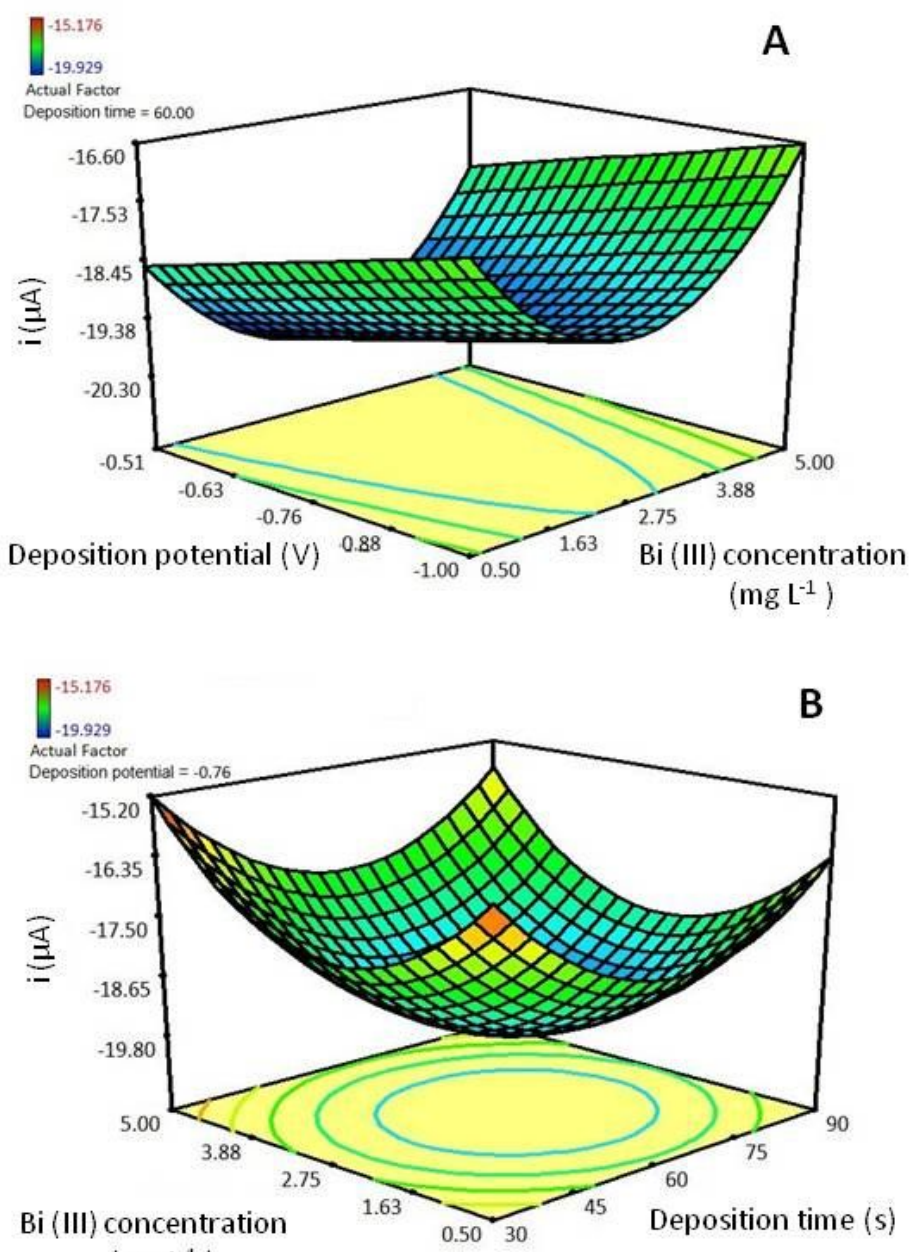
$\left(\mathrm{mg} \mathrm{L}^{-1}\right)$

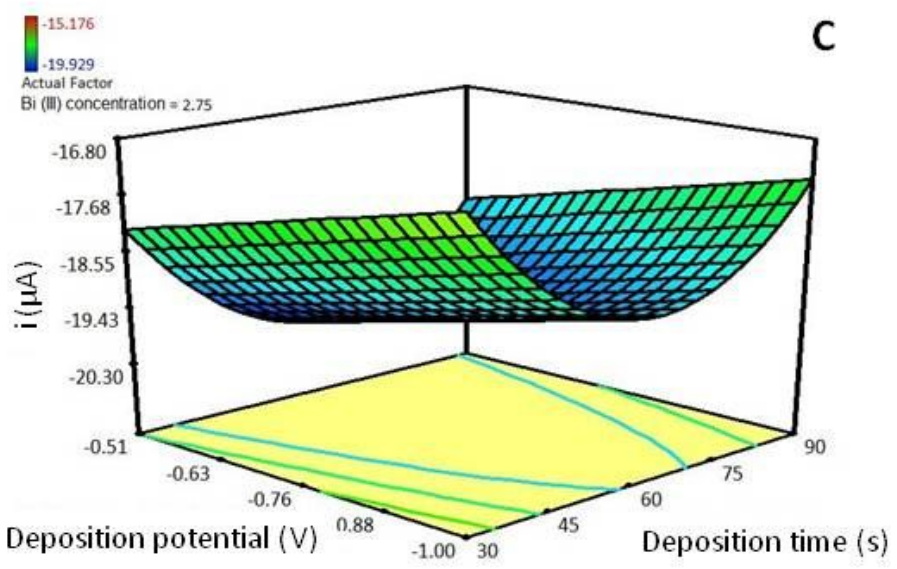




\section{Figure 3}

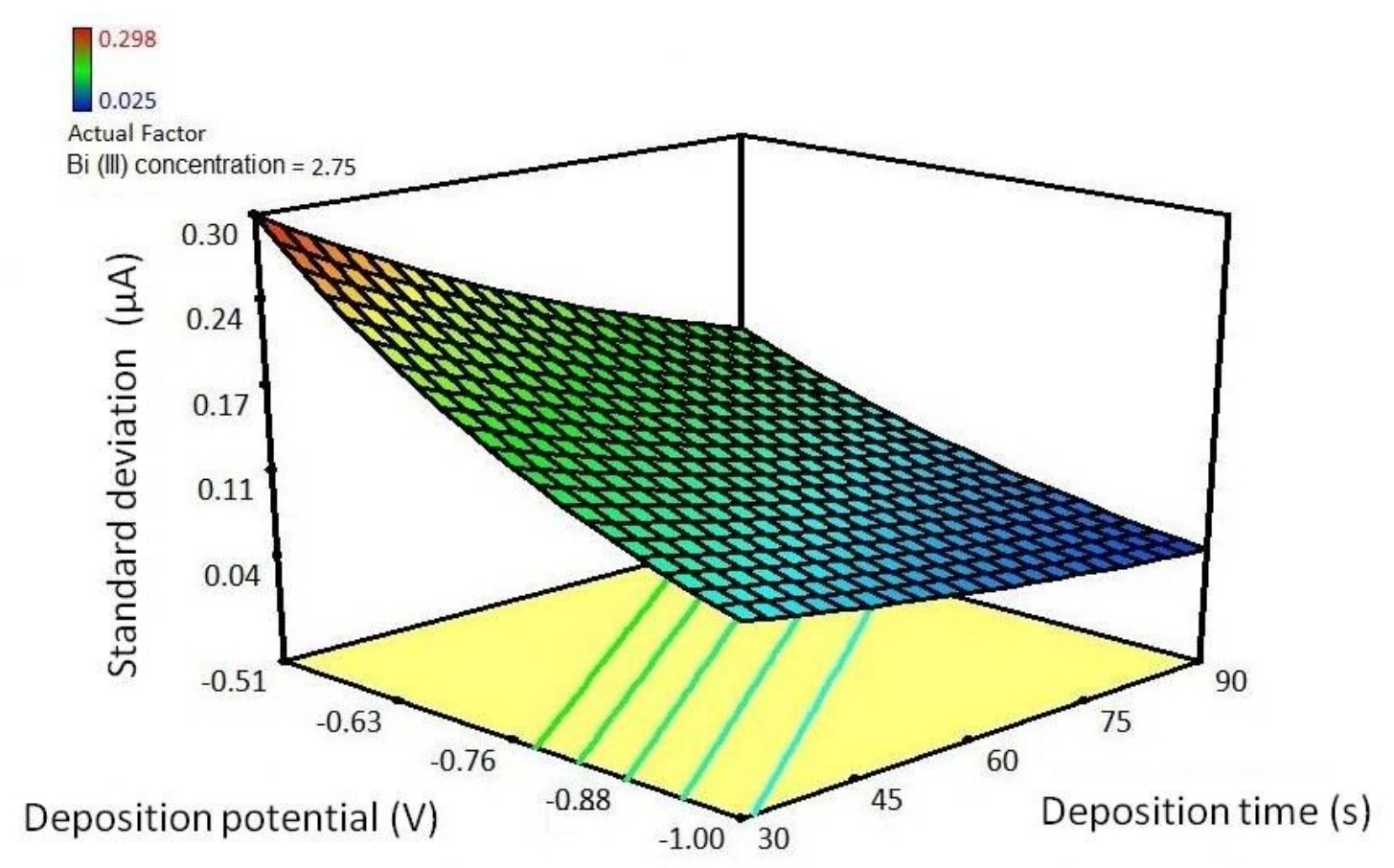

ACS Paragon Plus Environment 


\section{Figure 4}
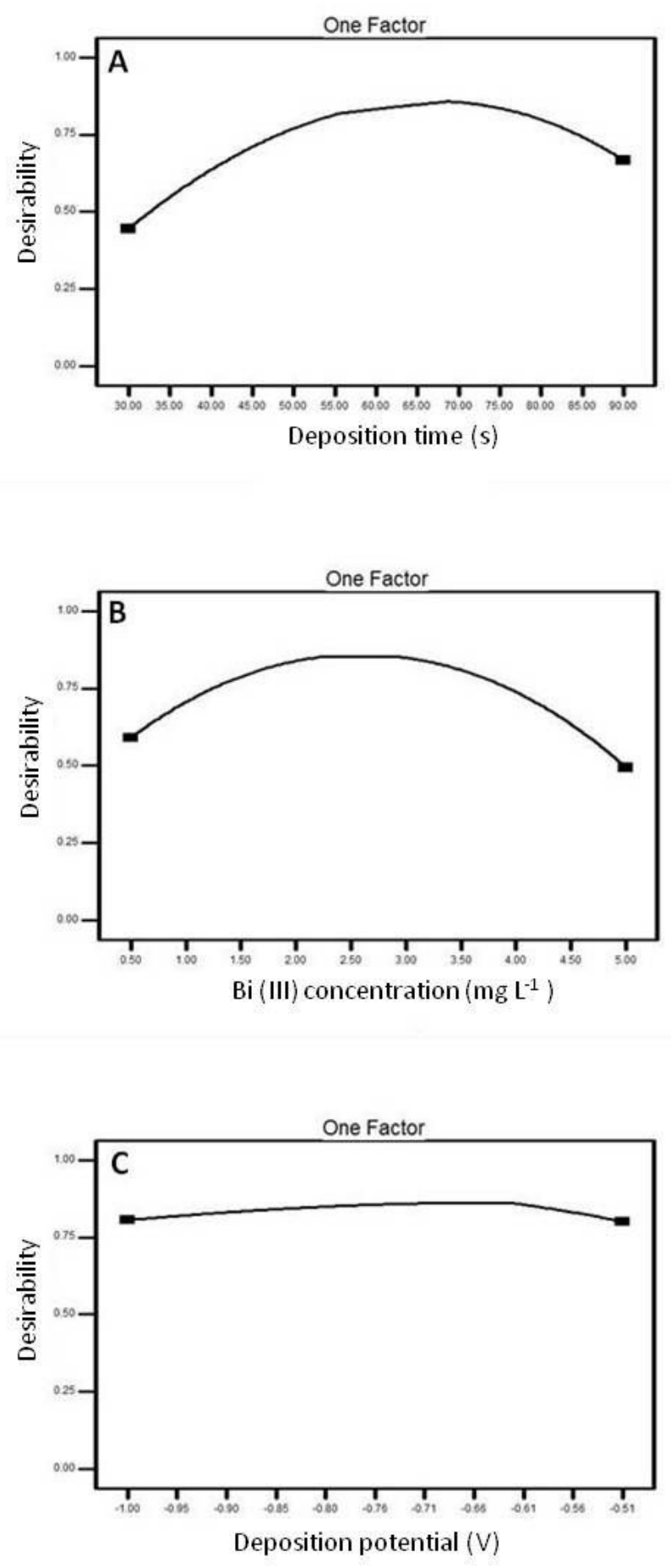

ACS Paragon Plus Environment 
Figure 5

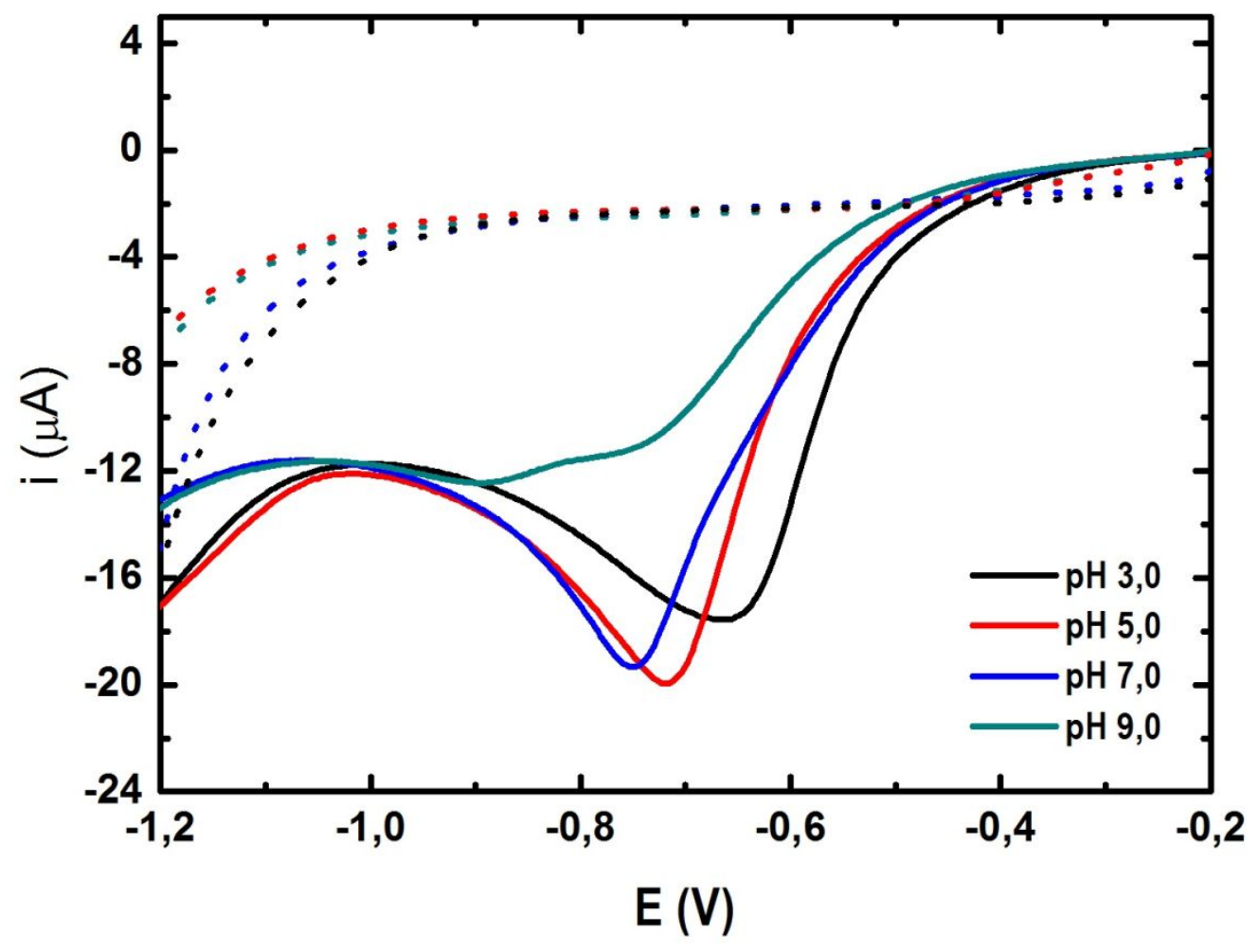

ACS Paragon Plus Environment 


\section{Figure 6}
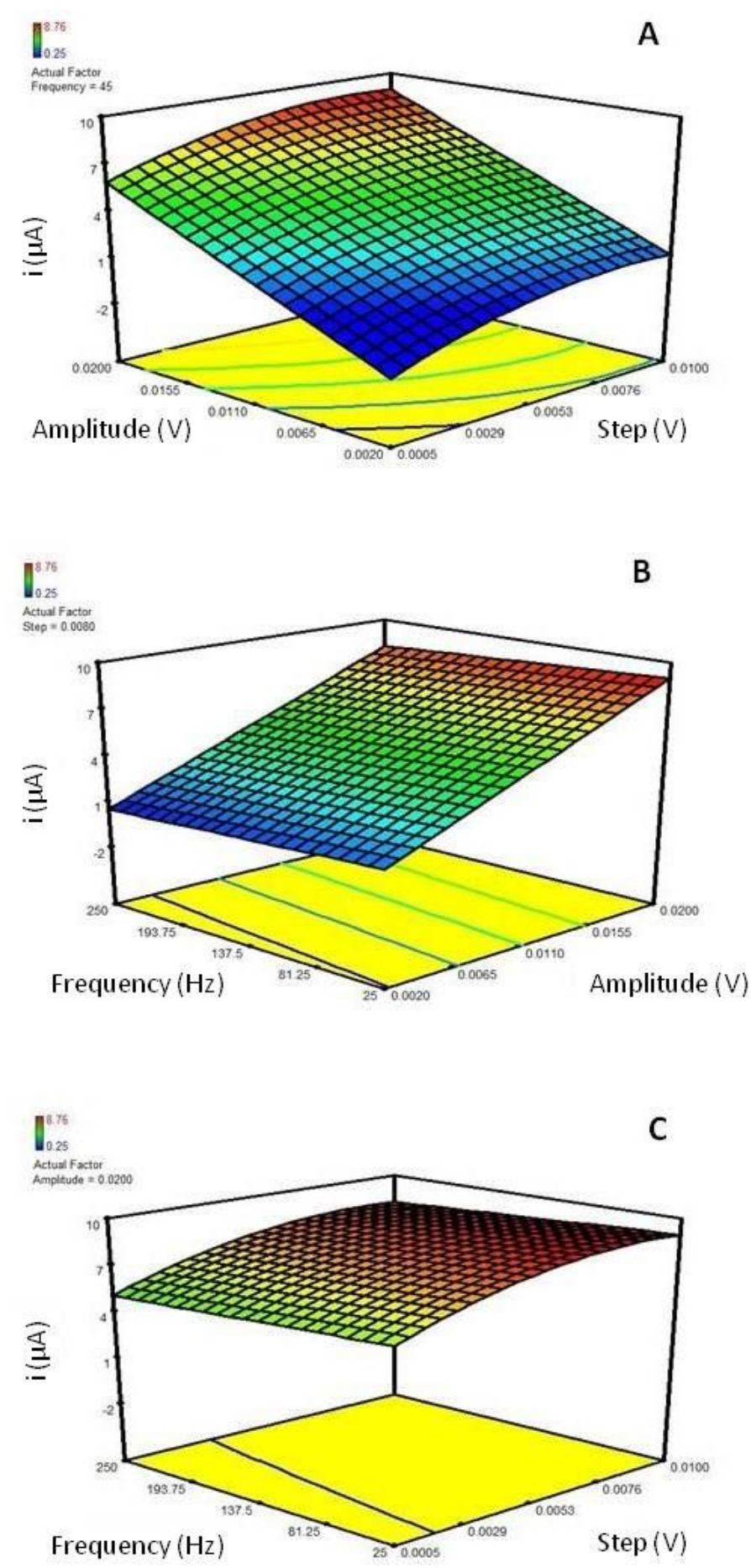


\section{Table of Contents graphic}

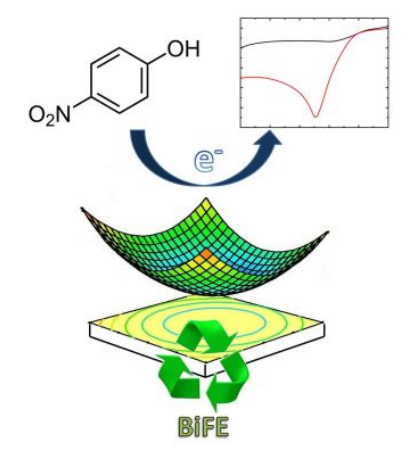

